\title{
Correction to: Combined uncertainty factor for sampling and analysis
}

Michael H. Ramsey ${ }^{1}$ - Stephen L. R. Ellison ${ }^{2}$

Published online: 18 December 2017

(C) Springer-Verlag GmbH Germany, part of Springer Nature 2017

\section{Correction to: Accred Qual Assur (2017) 22:187-189} https://doi.org/10.1007/s00769-017-1271-y

In the penultimate paragraph of the original publication, a confidence interval of $93 \mathrm{mg} / \mathrm{kg}$ to $971 \mathrm{mg} / \mathrm{kg}$ was reported. These values should be $114.5 \mathrm{mg} / \mathrm{kg}$ to $786.2 \mathrm{mg} / \mathrm{kg}$.
The intended exponent in the calculation was given as a multiplicative factor. The correct calculation is $300 / 1.619^{2}$ to $300 \times 1.619^{2}$, since the expanded uncertainty factor is $U F=\left(u^{\prime}\right)^{k}$, in this case giving $U F=\left(u^{\prime}\right)^{2}$.

The original article can be found online at https:// doi.org/10.1007/s00769-017-1271-y.

Michael H. Ramsey

m.h.ramsey@sussex.ac.uk

1 University of Sussex, Brighton, UK

2 LGC, Teddington, UK 